\title{
Effect of Grafted Chain Length on Hemostatic Activity of N-Alkylated Chitosan
}

\author{
Mengyuan LIU, Jian YANG, Jing GUAN, Shujie HUANG, Zhihong LI \\ Institute of Medical Equipment \\ Academy of Military Medical Sciences \\ Tianjin, China \\ e-mail: 1719517037@qq.com,yangjian-tj@eyou.com,13920075738@163.com,shujiehuang@126.com, lezivon@163.com
}

\author{
Miaolei JING \\ Department of Textile \\ Tianjin Polytechnic University \\ Tianjin, China \\ e-mail: jingmiaolei@126.com
}

\begin{abstract}
This study aimed to synthesize N-alkylated chitosan derivates with similar degree of substitution (DS) and alkyl groups of different carbon chain lengths via reductive alkylation, and then to compare their coagulation properties. Structural properties of the $\mathrm{N}$-alkylated chitosan derivates were characterized by Fourier transform infrared spectroscopy, elemental analysis and ${ }^{1} \mathrm{H}$ nuclear magnetic resonance spectroscopy. Their pro-coagulant properties were evaluated by detecting whole blood clotting time and performing TEG test. Pro-coagulant mechanisms of the $\mathrm{N}$ alkylated chitosan derivates were explored by detecting intracellular $\mathrm{Ca}^{2+}$ concentration in platelets and $\mathbf{P}$-selectin expression on platelets. We successfully prepared $\mathbf{N}$-alkylated chitosan derivates with a DS of $32.88 \%-39.78 \%$, including NACS6, NACS12 and NACS18. Our experimental findings showed that all $\mathrm{N}$-alkylated chitosan derivates (NACS6, NACS12, NACS18) have outstanding procoagulant effects, and the longer alkyl chain, the better procoagulant ability. However, $\mathrm{N}$-alkylated chitosan cannot activate platelets, and its procoagulant mechanism remains to be further studied in future. Based on the above results, this paper makes a conjecture about the coagulation mechanism of $\mathrm{N}$-alkylation chitosan.
\end{abstract}

\section{Keywords-chitosan; alkylation; blood coagulation}

\section{INTRODUCTION}

Surgical treatment, battlefield injuries and sudden accidents in daily life inevitably cause traumatic hemorrhage, and even death due to excessive blood loss. Hemostasis has increasingly become a research hot spot in the medical field.

Chitosan is a product by alkaline deacetylation of chitin with the degree of deacetylation over $55 \%$. It is a highcontent, low-cost polysaccharide with abundant and widely distributed sources, which is regarded as the sixth life element by modern science ${ }^{1}$. Not only does chitosan have good biocompatibility, biodegradability and anti-bacterial ability, but also dose it owe good hemostatic capacity ${ }^{2}$. However, pure chitosan has limited hemostasis potential, which is only suitable for a small area but not a serious bleeding wound ${ }^{3}$. Consequently, modification is a vital method to enhance the coagulation performance of chitosan.

In recent years, the modification of chitosan has gained increasing attention by experts and scholars. A study by Yao et $\mathrm{al}^{4}$. showed guanidinylated chitosan powder was found to have the ability to shorten the clotting time, however, the improvement in the procoagulant properties was still limited.

The other study based on a rat model of heparin-induced liver injury showed carboxymethylated chitosan could significantly reduce bleeding amount and increase hemostasis rate as compared with oxidized regenerated cellulose (Surgicel) $)^{5}$. Meanwhile, carboxymethylated chitosan was also confirmed to have better antiinflammatory effect and promote wound healing. $\mathrm{N}$ carboxyethyl chitosan fiber prepared by Mao et $\mathrm{al}^{6}$. exhibited enhanced abilities of hemostasis and liquid absorption in comparison with conventional chitosan dressings, which could not only avoid infections, but also accelerate wound healing. Dowling et $\mathrm{al}^{7}$.showed benzenen-octadecyl chitosan with a degree of substitution (DS) of $2.5 \%$ had obviously increased hemostasis capacity either in vitro or vivo. However, little is reported on the changes in the hemostasis ability of chitosan following modification using different alkyl chains. In the present study, we prepared a series of N-alkylated chitosan derivates (NACS6, NACS12, NACS18) with similar DS via reductive alkylation, verified their main functional groups using Fourier transform infrared spectroscopy (FTIR) and $1 \mathrm{H}$ nuclear magnetic resonance spectroscopy ( $\left.{ }^{1} \mathrm{H}-\mathrm{NMR}\right)$, detected the effect of alkyl chain length on their hemostasis ability using whole blood clotting time and thromboelastography (TEG), explored their pro-coagulant mechanism by detecting $\mathrm{Ca}^{2+}$ concentration in platelets and platelet surface P-selectin expression, and finally makes a conjecture about the coagulation mechanism of $\mathrm{N}$-alkylated chitosan. 


\section{MATERIALS AND METHODS}

\section{A. Materials}

Chitosan, the molecular weight of 98,000, was purchased from Shandong Aokang Biotechnology Co., Ltd., (Shandong Province, China); hexanal, dodecanal, PBS from Tianjin Ruibo Star Biotechnology Co., Ltd. (Tianjin, China); octadecanal from J \& K Scientific (Tian, China); deuterium (heavy water) and deuterated hydrochloride from Tianjin Weikai Bioeng Ltd. (Tianjin, China); and Fluo-4AM, Triton, FITC from Tianjin Brett Biotechnology Co., Ltd. (Tianjin, China).

Blood samples were extracted from the heart of adult male New Zealand rabbits that were purchased from the Animal Center of the Academy of Military Medical Sciences (Beijing, China).

\section{B. Experimental Procedures}

1) Preparation of $\mathrm{N}$-alkylated chitosan: Chitosan $2 \mathrm{~g}$ was dissolved in $200 \mathrm{~mL}$ of $1 \%$ acetate solution with the addition of appropriate amount of aldehyde at different proportions of aldehyde to chitosan, stirring at room temperature for 12 hours. Then, the $\mathrm{pH}$ value of the reaction solution was set to 5 by adding $10 \% \mathrm{NaOH}$, and $\mathrm{NaBH}_{3} \mathrm{CN}$ at a ratio of 1:1 $\left(\mathrm{NaBH}_{3} \mathrm{CN}\right.$ :aldehyde) was added, stirring for 2 another hours. The $\mathrm{pH}$ of the reaction solution was then adjusted again to 10 with the addition of $10 \% \mathrm{NaOH}$ solution. The precipitated product was filtered, washed with distilled water until neutral, repeatedly rinsed with ethanol to remove redundant aldehydes and inorganics, and then freeze-dried to obtain the end product.

TABLE I. RATIO OF ALDEHYDE TO CHITOSAN

\begin{tabular}{|c|c|c|c|}
\hline Aldehyde & $\begin{array}{c}\text { Amino/Aldehyde } \\
(\mathbf{m o l} / \mathbf{m o l})\end{array}$ & $\begin{array}{c}\text { Aldehyde } \\
(\mathbf{m L} / \mathbf{g})\end{array}$ & Chitosan(g) \\
\hline Hexanal & $2: 1$ & $0.450 \mathrm{ml}$ & 2.000 \\
\hline Dodecyl & $1: 3$ & $5.565 \mathrm{ml}$ & 2.000 \\
\hline N-octadecanal & $1: 3$ & $6.658 \mathrm{~g}$ & 2.000 \\
\hline
\end{tabular}

2) FTIR detection: With the aid of $\mathrm{KBr}$ tableting method, the sample to be tested was mixed with potassium bromide powder and ground into fine powder that was made into a stipulated flake. The flake was tested for its absorbance in the range of $400-4,000 \mathrm{~cm}^{-1}$, and plotted by origin software. FTIR spectra of different samples were then compared.

3) ${ }^{l} H$-NMR: NMR spectrometer was used to record the spectra of atoms under the resonance, based on which we inferred the position of the atoms on the carbon skeleton. The number of its absorption peaks contributes to the determination of the chemical environment of hydrogen. The peak area ratio reflects the proportion ratio of the number of hydrogen atoms in different chemical environments.

4) Element analysis: A Vario EL cube elemental analyzer was used to determine the contents of $\mathrm{C}$ and $\mathrm{N}$ in different samples in the same system. The degree of deacetylation and the DS of N-alkylated chitosan derivates were calculated according to formula 1 and formula 2 , respectively.

$$
\begin{gathered}
\frac{[(1-\mathrm{x}) \times 8+\mathrm{x} \times 6] \times 12}{14 \times 100}=\frac{C}{N} \\
\frac{[(1-\mathrm{x}) \times 8+\mathrm{x} \times 6+\mathrm{DS} \times \mathrm{n}] \times 12}{14 \times 100}=\frac{C}{N}
\end{gathered}
$$

In which,

$\mathrm{x}$--- Deacetylation degree of chitosan

DS --- Degree of alkyl substitution

$\mathrm{C}, \mathrm{N}$--- $\mathrm{C}, \mathrm{N}$ element percentage

$\mathrm{n}$--- The number of $\mathrm{C}$ atoms in alkyl aldehyde: $\mathrm{n}-6,12,18$

5) Detection of whole blood clotting time: A sample of 5 mg was placed into a test tube and placed at $37{ }^{\circ} \mathrm{C}$ for 3 minutes followed by the addition of anticoagulant blood (1 $\mathrm{mL}$; the mixture of fresh blood and sodium citrate at a ratio of 9: 1). Then, the sample was incubated at $37{ }^{\circ} \mathrm{C}$ for another 3 minutes followed by the addition of $775 \mathrm{uL}$ of $\mathrm{CaCl}_{2}$ solution $(25 \mathrm{mmol} / \mathrm{L})$. The test tube was tilted every 10 seconds to observe whether the blood clotted, and the time from the addition of $\mathrm{CaCl}_{2}$ solution to blood coagulation was recorded as the whole blood clotting time. The above procedures were repeated thrice for each sample.

6) Thromboelastography test: TEG is a test with time as horizontal ordinate to reflect blood clotting process and clot strength $^{8}$. An anticoagulated whole blood sample $(1 \mathrm{~mL})$ and a sample to be tested (10 $\mathrm{mg})$ were mixed well in a centrifuge tube and pipetted into a test cup. Then, $20 \mathrm{uL}$ of $0.2 \mathrm{~mol} / \mathrm{L} \mathrm{CaCl}_{2}$ solution was added. TEG curve was recorded using computer ${ }^{9}$, whose the main indicators were 1) reaction time $(\mathrm{R})$ : the time from the initiation of blood coagulation to the formation of fibrinogen, mainly reflecting the quality and quantity of coagulation factors; 2) coagulation time $(\mathrm{K})$ : the time to reach a $20 \mathrm{~mm}$ amplitude of thrombus from the beginning of blood coagulation; 3 ) Angle $\alpha$ : reflecting blood clotting speed; 4) maximum amplitude (MA): reflecting the maximum intensity of thrombosis $^{10,11}$.

7) Determination of $\mathrm{Ca}^{2+}$ concentration in platelets: A sample of anticoagulant whole blood was centrifuged at $200 \times \mathrm{g}$ for 20 minutes, and the upper plasma was aspirated and centrifuged at $1200 \times \mathrm{g}$ for 15 minutes. Then the supernatant was transferred and platelet deposition was obtained. Finally the platelet product deposited was mixed well with $10 \mathrm{uL}$ of Fluo-4AM, and incubated at $37{ }^{\circ} \mathrm{C}$ for 20 minutes, after which $50 \mathrm{uL}$ of PPP, was pipetted into a platelet suspension. The concentrated platelet suspension was then dropped into EP tubes containing $1 \mathrm{mg}$ of sample to be tested and incubated for 15 minutes at $37{ }^{\circ} \mathrm{C}$. Then, $100 \mathrm{uL}$ of $0.1 \%$ Triton was added to each EP tube and shaken vigorously for 5 minutes and centrifuged at $12,000 \times \mathrm{g}$ for 5 minutes. The supernatant of $100 \mathrm{uL}$ was placed into a black 96-well plate for fluorescence detection 
at a wavelength of $\mathrm{Ex} / \mathrm{Em}=488 / 506 \mathrm{~nm}$. Blank control group shared the same procedures as above mentioned except for the addition of materials.

8) Determination of platelet surface P-selectin: A sample of anticoagulant whole blood was centrifuged at $200 \times$ g for 20 minutes, and the supernatant was removed to get platelet-rich plasma (PRP). After addition of $100 \mathrm{uL}$ of PRP, a test sample (2 mg) was incubated at $37{ }^{\circ} \mathrm{C}$ for 30 minutes. Then, $1 \mathrm{~mL}$ of PBS was added to each tube, and the sample was rinsed and removed. The remaining liquid was centrifuged at $1200 \times \mathrm{g}$ for 10 minutes. The supernatant was discarded and $20 \mu \mathrm{L}$ of fluorescein isothiocyanate (FITC) fluorescently labeled P-selectin rabbit monoclonal antibody (fluorescein to antibody ratio $1: 100$ ) was added to each tube. After incubation at $4{ }^{\circ} \mathrm{C}$ in dark for 20 minutes, $0.9 \mathrm{~mL}$ of PBS was added and mixed well with the sample. Subsequently, the sample passed a 300 mesh sieve, and the final determination of the sample was done by flow cytometry. Blank control group shared the same procedures except for the addition of materials.

\section{RESULTS}

\section{A. FTIR}

The FTIR spectra of NACS6, NACS12 and NACS18 were shown in Figure 1. After chemical modification by alkylation, a new alkane bending vibration band appeared at about $1466 \mathrm{~cm}^{-1}$. The stretching vibration band appeared at 2800-2900 $\mathrm{cm}^{-1}$ and 2900-3000 $\mathrm{cm}^{-1}$, which strengthened with the increasing length of grafted alkyl chain. All of above proves indicating that an alkyl group has replaced a hydrogen atom on the amino group of chitosan. Meanwhile, the absorption band of nitrogen-hydrogen bond on the amino group of chitosan strengthened at $1560 \mathrm{~cm}^{-1}$, while the absorption band of amino group disappeared at $1594 \mathrm{~cm}^{-}$ 1 , indicating that a substitution reaction occurred on the amino group and $\mathrm{N}$-alkylated chitosan was successfully synthesized $^{12}$.

\section{B. ${ }^{1} H-N M R$}

As shown in Figure 2, the peak values of chitosan were $1.9\left(\mathrm{CH}_{3}, \mathrm{CH}_{3}-\mathrm{CO}-\right), 4.4(\mathrm{H} 1), 3.0(\mathrm{H} 2), 3.3-3.9(\mathrm{H} 3, \mathrm{H} 4$, $\mathrm{H} 5$, H6), respectively; and the peak values of NACS6 were 2.9-3.2 (NH-CH$\left.-\left(\mathrm{CH}_{2}\right)_{4}-\mathrm{CH}_{3}\right), 1-2.0\left(\mathrm{NH}-\mathrm{CH}_{2}-\left(\mathrm{CH}_{2}\right)_{4}-\mathrm{CH}_{3}\right)$ and $0.7\left(\mathrm{NH}-\mathrm{CH}_{2}-\left(\mathrm{CH}_{2}\right)_{4}-\mathrm{CH}_{3}\right)$. For the NMR spectra of NACS12 and NACS18, 2.9-3.0 and 0.9-2.0 ppm indicated methylene hydrogens on the dodecyl and octadecyl groups grafted onto the chitosan backbone, respectively. The methyl hydrogen on the NACS12 and NACS18 backbones was around 0.7 and $0.9 \mathrm{ppm}$, respectively. The results of $1 \mathrm{H}-\mathrm{NMR}$ affirmed that all the three kinds of alkyl groups (hexane, dodecyl and octadecyl) were successfully grafted onto the amino group of chitosan ${ }^{13}$.

\section{Elemental Analysis}

The degree of deacetylation of chitosan was about $69 \%$. By controlling the ratio of amino group to aldehyde group, the DS of the N-alkylated chitosan with different alkyl chain lengths was kept at about $35 \%$. Consequently, we could compare the hemostatic effects of N-alkylated chitosan with different alkyl chain lengths at similar DS (Table 2).

\section{In vitro whole Blood Clotting Time}

As shown in Figure 3, the whole blood clotting time for pure blood, pure chitosan, N-alkylated chitosan with different alkyl chain lengths (NACS6, NACS12, NACS18) was about 200, 145, 55, 40, 30 seconds, respectively. By calculation using Origin, there was no significant difference in the whole blood clotting time of chitosan and pure blood $(\mathrm{P}>0.05)$. The whole blood clotting time for NACS6, NACS12 or NACS18 was significantly different from that of chitosan and pure blood $(\mathrm{P}<0.05)$. These experimental findings indicate a great improvement in the coagulation performance of $\mathrm{N}$-alkylated chitosan compared with pure chitosan. The longer alkyl chain, the better pro-coagulant ability.

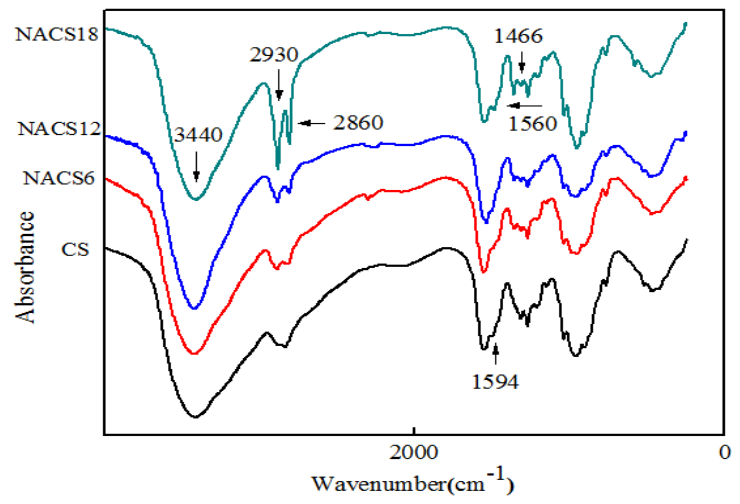

Figure 1. FTIR spectra.

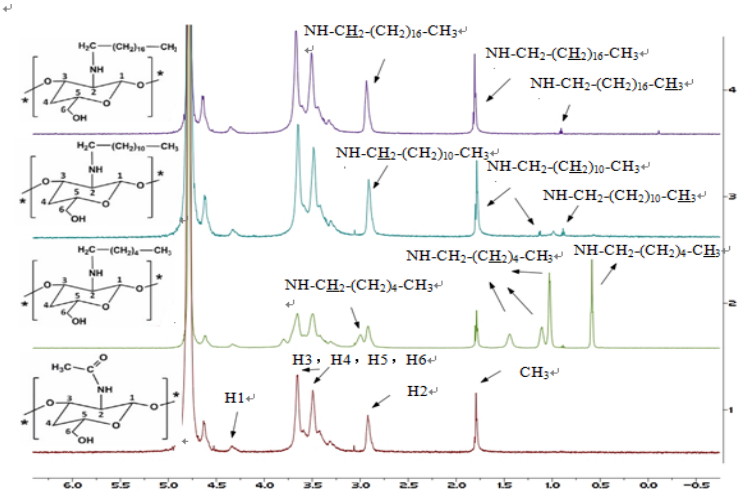

Figure 2. ${ }^{1} \mathrm{H}-\mathrm{NMR}$ findings of chitosan and $\mathrm{N}$-alkylated chitosan.

TABLE II. CONTENT OF C AND N ELEMENTS AND THE DEGREE OF SUBSTITUTION

\begin{tabular}{|c|c|c|c|c|}
\hline Samples & $\begin{array}{c}\text { Amino/A } \\
\text { ldehyde } \\
\text { (mol/mol } \\
2: 1\end{array}$ & $\mathbf{C}(\%)$ & $\mathbf{N}(\%)$ & DS(\%) \\
\hline NACS6 & $48.18 \pm 0.72$ & $6.54 \pm 0.05$ & $32.88 \pm 2.29$ \\
\hline NACS12 & $1: 3$ & $51.06 \pm 0.06$ & $5.59 \pm 0.02$ & $33.67 \pm 0.25$ \\
\hline NACS18 & $1: 3$ & $54.82 \pm 0.08$ & $4.64 \pm 0.03$ & $39.78 \pm 0.67$ \\
\hline
\end{tabular}




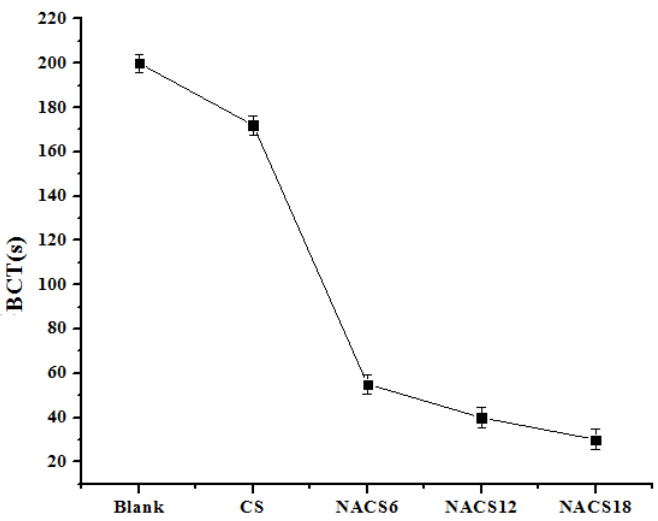

Figure 3. Whole blood clotting time of pure chitosan and $\mathrm{N}$-alkylated chitosan.

\section{E. TEG}

In the TEG test, the coagulation performance of the test sample was detected instead of studying a single component in the blood. As shown in Table 3, the $\mathrm{R}$ values of chitosan and $\mathrm{N}$-alkylated chitosan were less than that of pure blood, and the $\mathrm{R}$ value of $\mathrm{N}$-alkylated chitosan was lower than that of chitosan. The longer grafted chain brings out the smaller $R$ value: $R_{\text {NACS6 }}>R_{\text {NACS12 }}>R_{\text {NACS18. }}$. Both chitosan and Nalkylated chitosan could reduce the time from the initiation of coagulation to the formation of fibrinogen. No significant differences in $\mathrm{K}$ value, $\alpha$ value and MA value, indicated that chitosan and $\mathrm{N}$-alkylated chitosan have no significant effect on the formation rate of blood clots, fibrin crosslinking speed and maximum strength of blood clots.

TABLE III. THE COAGULATION PERFORMANCE OF THE TEST SAMPLE MIXED AT 37 OC.

\begin{tabular}{|c|c|c|c|c|}
\hline Samples & $\mathbf{R}(\mathbf{m i n})$ & $\mathbf{K}(\mathbf{m i n})$ & $\boldsymbol{\alpha}(\mathbf{d e g})$ & $\begin{array}{c}\text { MA } \\
(\mathbf{m m})\end{array}$ \\
\hline Blood & 11.3 & 3.3 & 52.3 & 69.9 \\
\hline Chitosan & 9.9 & 2.5 & 63.4 & 72.6 \\
\hline NACS6 & 6.2 & 2.7 & 68.2 & 72.1 \\
\hline NACS12 & 5.4 & 2.3 & 70.5 & 72.4 \\
\hline NACS18 & 4.3 & 3.0 & 52.9 & 70.7 \\
\hline
\end{tabular}

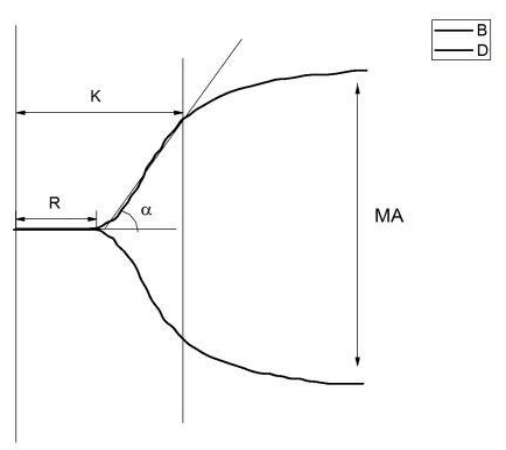

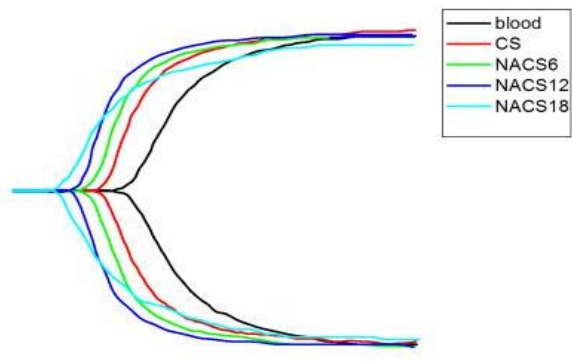

Figure 4. (a). Schematic diagram of TEG parameters; (b). TEG image of chitosan and $\mathrm{N}$-alkylated chitosan.

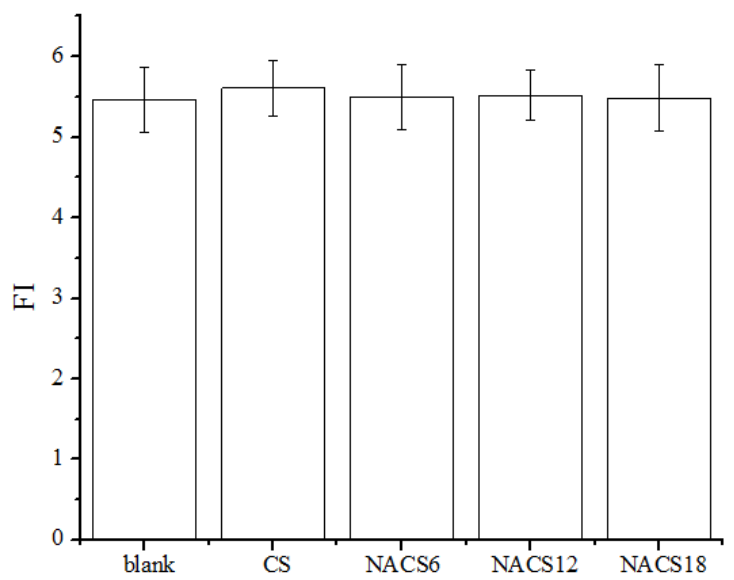

Figure 5. Figiure 5. Effect of N-alkylated chitosan on the intracellular $\mathrm{Ca} 2+$ concentration in platelets.

\section{F. Platelet $\mathrm{Ca}^{2+}$ Concentration}

Compared with the blank control group, the intracellular $\mathrm{Ca}^{2+}$ fluorescence intensity in platelets showed no significant changes after intervention with chitosan or $\mathrm{N}$ alkylated chitosan $(\mathrm{P}>0.05$; Figure 5). This indicates that $\mathrm{N}$-alkylated chitosan has no significant effect on intracellular $\mathrm{Ca}^{2+}$ concentration in platelets, regardless of the length of alkyl chains. That is to say, $\mathrm{N}$-alkylated chitosan cannot cause changes in the intracellular $\mathrm{Ca}^{2+}$ concentration in platelets.

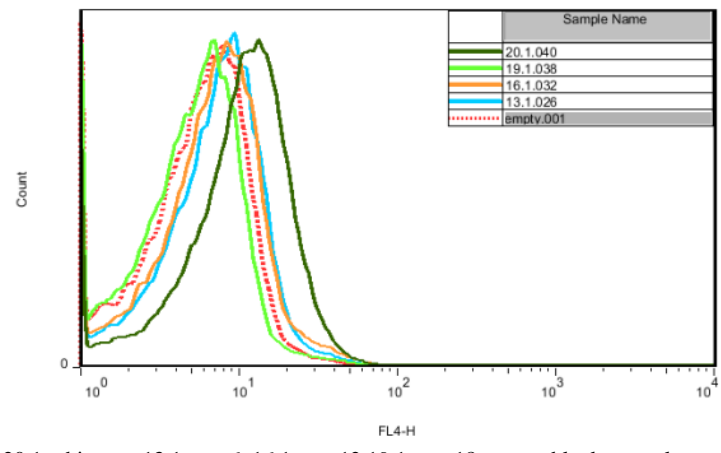

Note: 20.1- chitosan, 13.1-nacs6, 16.1-nacs12,19.1-nacs18, empty-blank control.

Figure 6. Expression of P-selectin on platelets. 


\section{G. Expression of P-Selectin on Platelets}

As shown in Figure 6, the curves of chitosan and Nalkylated chitosan shifted slightly compared with the blank control group, but the trend, peak height, peak width were basically the same with those in the blank control group. Neither chitosan nor N-alkylated chitosan could significantly promote the expression of P-selectin, indicating that chitosan and $\mathrm{N}$-alkylated chitosan have no significant effect on platelet adhesion and activation, which is consistent with the conclusion from the intracellular $\mathrm{Ca}^{2+}$ determination. This enables us to conclude that the procoagulant effect of $\mathrm{N}$-alkylated chitosan is not aroused by platelet activation and adhesion.

\section{H. The Coagulation Mechanism of N-Alkylated Chitosan}

It is known that n-alkyl chitosan does not promote blood coagulation by activating coagulation factors and platelets, thus we can guess that its coagulation mechanism is associated with red blood cells. In general, the materials are used in the biochemical methods such as electrostatic adsorption, wrapping and other physical methods or physiological stimulation to act on the red blood cells, causing changes and accumulations to them. Red blood cells are the main components of blood clots and linchpin of clotting process. We believe that n-alkylated chitosan should affect red blood cells in a physical manner. Physical methods can be divided into two ways: by means of electrostatic adsorption, which can bind red blood cells and using the alkyl chain of grafting. Chitosan contains a positively charged amino group, which can attract red blood cells with negative charge, which causes the red blood cells to stick together and form a blood clot. Although the amino group in n-alkylated chitosan is particully replaced by the alkyl chain, the substitution is not high, so it still has a positive charge.If $\mathrm{N}$ - alkylated chitosan promotes clotting by electrostatic attraction of red blood cells, due to the positive charge of chitosan is larger than the particularly replaced amino by $\mathrm{N}$-alkylated chitosan. So in theory the chitosan fluorescence should have condensed more red blood cells than $\mathrm{N}$-alkylated chitosan and coagulated better. But results of a series of vitro blood coagulation experiments of this topic show that $\mathrm{N}$-alkylated chitosan coagulant's effect is better when the graft alkyl carbon chain is longer. Accordingly, the electrostatic of red blood cells is not the main reason of $\mathrm{N}$-alkylated chitosan coagulant, and is likely to be due to electrostatic attraction and alkyl side chain's coverage on red blood cells, making free red blood cells into aggregation, and physical coil coating should be dominant. Researchers believe that hypothesized mechainisms of N-alkylated chitosan hemostatic's effect includes the fixed effect of the hydrophobic alkyl chain inserting the blood cell membrane, thus blood cells will be connected into a gel network by the biological polymer chains, it may cause clotting. And when the alkyl carbon chain is longer and its hydrophobicity is better, the cell's fixation is stronger. When the side chain of $\mathrm{N}$-alkylated chitosan is long, it's more likely to form a gel network and a better coverage on the blood cells, so the coagulating effect is better.
In conclusion, N-alkylated chitosan's hemostatic mechanism is as follows: after cogulation system starts, internal and external coagulation pathways are activated, and a variety of clotting factors under the participation of platelets start to play a role. At the same time, $\mathrm{N}$-alkylated chitosan aggregate blood cells by electrostatic attraction and alkyl side chain's winding when the fibrinogen is converted into fibrin and forms a network structure, N-alkylated chitosan will interlace blood cells and fibrin network, covering and fixing on blood cells again, which accelerates the blood cell's aggregation, so as to accelerated the formation of thrombus, and achieve the purpose of accelerating blood's coagulation. In this way, N-alkylated chitosan greatly promotes the process of coagulation, shortering the time required for clotting.

\section{DISCUSSION}

In this study, we successfully synthesized $\mathrm{N}$-alkylated chitosan derivates with similar DS and alkyl groups of different carbon chain lengths via reductive amination. The synthesized products were also confirmed to be N-alkylated chitosan derivates by FTIR spectrum and ${ }^{1} \mathrm{H}-\mathrm{NMR}$. Coagulation performance of $\mathrm{N}$-alkylated chitosan derivates was tested based on the whole blood clotting time and TEG tests. In the test of whole blood clotting time, the procoagulant effect of $\mathrm{N}$-alkylated chitosan could be directly judged by observing the blood clotting time in the test tube. Compared with the whole blood and pure chitosan, $\mathrm{N}$-alkylated chitosan significantly shortened the clotting time, and the longer grafted chain resulted in the shorter clotting time. In the TEG test, the $\mathrm{R}$ values for three kinds of $\mathrm{N}$-alkylated chitosan derivates were as follows: $\mathrm{R}_{\mathrm{NACS} 6}>$ $\mathrm{R}_{\mathrm{NACS12}}>\mathrm{R}_{\mathrm{NACS18}}$, indicating both chitosan and N-alkylated chitosan can shorten the time from the initiation of coagulation to the formation of fibrinogen, and the latter one offers the better effect. For N-alkylated chitosan derivates, the longer grafted chain length induced the shorter time. However, there was no significant difference in $\mathrm{K}, \alpha$ and MA values among different groups, indicating that chitosan and $\mathrm{N}$-alkylated chitosan have no significant effects on the formation rate of blood clots, fibrin cross-linking rate and maximum strength of blood clots.

$\mathrm{Ca}^{2+}$ is vital for platelet physiology ${ }^{14,15}$. Changes in intracellular signaling alter the structure of GPIIbIIIa, followed by fibrinogen-mediated platelet aggregation, whereas intracellular signal transduction depends on cytoplasmic $\mathrm{Ca}^{2+16}$. Therefore, variation in intracellular $\mathrm{Ca}^{2+}$ concentrations contribute to reflecting changes in platelet physiology induced by the material to be tested. During the determination of intracellular $\mathrm{Ca}^{2+}$ concentrations, the intracellular $\mathrm{Ca}^{2+}$ fluorescence intensity after the platelet was intervened with the test sample did not significantly differ from that in the blank control group. This indicates that both chitosan and $\mathrm{N}$-alkylated chitosan have no significant effect on intracellular $\mathrm{Ca}^{2+}$ concentration in platelets, no matter how long the alkyl chain length is. Chitosan and $\mathrm{N}$-alkylated chitosan can not cause changes in platelet intracellular $\mathrm{Ca}^{2+}$ concentrations.

$\mathrm{P}$-selectin is a component of resting platelet alpha 
granule membrane. Platelet adhesion and pseudopodia extension are thought to be mediated by P-selectin (CD62p) and integrin (GPIIbIIIa) ${ }^{17,18}$. During the determination of Pselectin expression, the curves of chitosan and $\mathrm{N}$-alkylated chitosan were basically the same in trend, peak height and peak width as compared with that of the blank control group. Neither chitosan nor N-alkylated chitosan could significantly promote P-selectin expression, proving that pure chitosan and $\mathrm{N}$-alkylated chitosan have no significant effect on platelet adhesion and activation. Therefore, we can draw the conclusion that platelet activation and adhesion cannot elicit the procoagulant action of $\mathrm{N}$-alkylated chitosans.

In summary, the N-alkylated chitosan has better procoagulant ability than pure chitosan, and those with increased graft chain alkyl groups exhibit a better clotting effect when their DS were similar. Either chitosan or Nalkylated chitosan can reduce the time from coagulation initiation to fibrinogen formation. Moreover, the $\mathrm{N}$ alkylated chitosan could shorten the clotting time than pure chitosan. For $\mathrm{N}$-alkylated chitosan derivates with different alkyl chain length, the longer grafted chain leads to the shorter clotting time. Overall, the $\mathrm{N}$-alkylated chitosan cannot increase platelet intracellular $\mathrm{Ca} 2+$ concentration and P-selectin expression on platelets, which shows its procoagulant effect is not triggered by platelet aggregation, activation and adhesion. In this paper, the hypothesis of the coagulation mechanism of n-alkylated chitosan is put forward, but no experimental verification is carried out, and further study is needed.

\section{ACKNOWLEDGMENT}

This study was financially supported by the National Natural Science Foundation of China (Grant No. 31570956). The authors contributed equally to this work.

\section{REFERENCES}

[1] Jiang T D, Chitosan, 2nd ed., Beijing: Chemical Industry Press, 2007.

[2] Lih E, Lee J S, Park K M and Park K D, "Rapidly curable chitosanPEG hydrogels as tissue adhesives for hemostasis and wound healing", Acta biomaterialia, vol. 8, Sep. 2012, pp. 3261-3269, doi:10.1016/j.actbio.2012.05.001.

[3] Gao J W, Liu W S and Han B Q, "Study of hemostatic effect of chitosanbased fibre", Journal of Anhui Agri. Sci., vol. 40, 2012, pp. 6458-6459, doi:10.13989/j.cnki.0517-6611.2012.11.078.
[4] Yao X P, Jing M L and Guan J, "Hemostatic property and cytotoxicity of the guanidine modified chitosan", Chinese Journal of Tissue Engineering Research, vol. 21, Feb. 2017, pp. 906-910, doi:10.3969/j.issn.2095-4344.2017.06.015.

[5] Fu D W, "Hemostatic effect of carboxymethylated chitosan and its blood safety evaluation", Ocean University of China, 2011.

[6] Mao J, Zhou Y S and Wu T, "High-absorbing chitosan dressings for hemostasis and wound healing", Chinese Journal of Tissue Engineering Research, vol. 20, 2016, pp. 2391-2396.

[7] Dowling M B, Kumar R, Keibler M A, Hess J R, Bochicchio G V, et. al., "A self-assembling hydrophobically modified chitosan capable of reversible hemostatic action", Biomaterials, vol. 32, May 2011, pp. 3351-3357, doi:10.1016/j.biomaterials.2010.12.033.

[8] Peng H T, "Thromboelastographic study of biomaterials", Journal of Biomedical Materials Research Part B: Applied Biomaterials, vol. 94, Apr. 2010, pp. 469-485, doi:10.1002/jbm.b.31626.

[9] Chen G Y, Ou Y X, Wu J H, Wang L H, Yang J H, et. al., "Comparison of thromboelastography and routine coagulation tests for evaluation of blood coagulation function in patients", Zhongguo Shiyan Xueyexue Zaizhi, vol. 233, Apri. 2015, pp. 546-551, doi:10.7534/j.issn. 1009-2137.2015.02.049.

[10] Wu H X, Zhang X , "Clinical application of thromboelastography in the coagulation system", Weixunhuanxue Zazhi. vol. 25, 2015, pp. 76-78.

[11] Lee D W, Powers K, Baney R, "Physicochemical properties and blood compatibility of acylated chitosan nanoparticles", Carbohydrate Polymers, vol. 58, Dec. 2004, pp. 371-377,doi:10.1016/j.carbpol.2004. 06.033

[12] Huang Y C, "Application for hemostasis of N-alkylated chitosan and their mechanism research", Jinan University, 2015.

[13] Chen Z, Yao X, Liu L, Guan J, Liu M, et. al., Blood Coagulation Evaluation of N-alkylated Chitosan, Carbohydrate Polymers, Oct. 2017, doi:10.1016/j.carbpol.2017.05.085.

[14] Jin J, Quinton T M, Zhang J, Rittenhouse S E and Kunapuli S P, "Adenosine diphosphate (ADP)-induced thromboxane A 2 generation in human platelets requires coordinated signaling through integrin $\alpha$ IIb $\beta 3$ and ADP receptors", Blood, vol. 99, 2002, pp. 193-198, doi:10.1182/blood.V99.1.193.

[15] Versteeg H H, Heemskerk J W, Levi M and Reitsma P H, "New fundamentals in hemostasis", Physiological Reviews, vol. 93, Jan. 2013, pp. 327-358, doi:10.1152/physrev.00016.2011.

[16] Stalker T J, Newman D K, Ma P, Wannemacher K M and Brass L F, "Platelet Signaling", Handbook of Experimental Pharmacology, vol 210, Jul. 2012, pp. 59-85, doi:doi.org/10.1007/978-3-642-29423-5_3.

[17] Lee B J, Jo I Y, Bu Y, Park J W, Maeng S, et. al., "Antiplatelet effects of Spatholobus suberectus via inhibition of the glycoprotein IIb/IIIa receptor", Journal of Ethnopharmacology, vol. 134, Mar. 2011, pp. 460-467, doi:10.1016/j.jep.2010.12.039.

[18] Zhao Y P, Jin P P, Zhou T and Wang X F, "Role of P-selectin in Cell Adhesion and Thrombosis", Chinese Journal of Cell Biology, vol. 29, 2007, pp. 22-26. 